\title{
Effect of a Guaiazulene-Containing Ointment on Nipple and Areola Area Health of Women
}

\author{
Cristian Furau1, Harry Grossmann1,2, Gheorghe Furau1, Jürgen Vormann ${ }^{3 *}$ \\ ${ }^{1}$ Department of Gynecology, Medical Faculty, Western University "Vasile Goldiş", Arad, Romania \\ ${ }^{2}$ MCS Pharma GmbH, Hanau, Germany \\ ${ }^{3}$ Institute for Prevention and Nutrition, Ismaning/Munich, Germany \\ Email: *vormann@ipev.de
}

Received 7 July 2016; accepted 27 August 2016; published 30 August 2016

Copyright (C) 2016 by authors and Scientific Research Publishing Inc.

This work is licensed under the Creative Commons Attribution International License (CC BY).

http://creativecommons.org/licenses/by/4.0/

(c) (i) Open Access

\begin{abstract}
Guaiazulene-containing ointments are routinely used for breast care during breastfeeding. It has also been proposed that nipple and areola area of non-breastfeeding women might benefit from use of this azulene. In a study with 51 women, it was investigated whether the use of a guaiazulene-containing ointment (Garmastan ${ }^{\circledR}$ ) would improve look, elasticity and sensitivity of nipple and areola area within 4 month daily application. About one third of study participants reported improvement in sensitivity, elasticity and look of the investigated area of the breast. Assessment of doctors revealed a clear improvement in elasticity and sensitivity of the nipple and areola area over study period. Nearly all women wished to continue the use of the ointment after end of the study. In conclusion, the use of Garmastan ${ }^{\circledR}$ ointment is able to improve sensitivity and elasticity of the nipple and areola area of the breasts of non-breastfeeding women.
\end{abstract}

\section{Keywords}

Guaiazulene-Containing Ointment, Breast Care, Breastfeeding

\section{Introduction}

The natural beauty of the breasts is of utmost importance to gain confidence into women's femininity. One aspect in this is the well-being of the nipple area and avoidance of irregular or fading areolas. The nipple and surrounding area, like other areas of skin, are subject to irritation, inflammation and infection. It has been shown that many benign and malignant processes [1] can affect the nipple and areola area. In some women, a negative change in nipple and areola appearance can lead to reduced self-confidence, lack of self-esteem and embarrass-

"Corresponding author.

How to cite this paper: Furau, C., Grossmann, H., Furau, G. and Vormann, J. (2016) Effect of a Guaiazulene-Containing Ointment on Nipple and Areola Area Health of Women. Journal of Cosmetics, Dermatological Sciences and Applications, 6, 167-173. http://dx.doi.org/10.4236/jcdsa.2016.64021 
ment. Furthermore, stimulation of the nipple-areola complex is important for sexual function. In a survey, $81.5 \%$ of interviewed women agreed that stimulation of the nipples or breasts increased their sexual arousal [2]. Of special importance for this highly sensitive area of the breasts is the time of pregnancy and especially lactation. During this time, the physical stress of breast milk production and breast-feeding might lead to benign infections and alterations [3]. Therefore, nipple care is important to keep the skin of the nipples and mammary areola supple and elastic, preventing the occurrence of erosion and infections, thus helping to protect the highly sensitive skin of this region.

For centuries, the curative and skin therapeutic properties of guaiazulene from the Guaiacum tree are known in the indigenous populations of the regions of North and South America. Guaiazulene is also helpful in dermatitis induced by radiation with clinically observed anti-inflammatory effects [4]. In Europe, the effectiveness of guaiazulene-containing ointments $\left(\right.$ Garmastan $\left.^{\circledR}\right)$ for breast skin care during pregnancy and especially during lactation is proven since decades [5]-[8]. In addition to the use in women's breast care, Garmastan ${ }^{\circledR}$ has also been used effectively as a new treatment option in diaper dermatitis [9]. Aside of these uses also in non-pregnant and non-breastfeeding women, this ointment might improve skin health and attractive appearance of the nipple and areola area. Therefore, in an observational study, we investigated whether a long-term use of a guaiazulenecontaining ointment would benefit women's breasts.

\section{Methods}

The efficiency of a guaiazulene-containing ointment $\left(0.05 \%\right.$ guaiazulene, Garmastan ${ }^{\circledR}$, Protina Pharm GmbH, Ismaning, Germany) was investigated over a period of 4 month application with regard to care of the nipple areola complex in non-pregnant, not recent birth giving and not breastfeeding women of different age. Participants visited the hospital because of routine control. The study achieved ethical approval by the ethical committee of the Emergency Clinical Hospital of Arad, Romania. All participants who agreed to participate were informed according to the Declaration of Helsinki and signed informed consent. Inclusion criteria for the study were: females, age above 18, minimum average of education and hygienic attitude. Exclusion criteria were: being pregnant or breastfeeding, recent birth giving, breast pathology in the past, mental disabilities or communication disorders, allergic reactions to content of Garmastan ${ }^{\circledR}$, severe acute or chronic disease. According to the availability of participants, a sample size of 50 women was estimated to be sufficient to verify significant effects. In total 51 women (age 21 - 64 years, average age 39 years) were included in the study; the participants had a mean BMI of 25 ( $\min 17$, max 37), number of pregnancies 0 - 7, mean 1.6.

The study was divided into four stages: initial consultation and 3 monthly follow up visits during a period of 4 months. At the first consultation, the known effects of Garmastan ${ }^{\circledR}$, the application, ongoing procedure, conditions for participating in the study and data privacy were explained. If eligible and willing to participate, participants were told to apply Garmastan ${ }^{\circledR}$ once a day on the nipple areola region. The participants were instructed to apply a quantity of Garmastan ${ }^{\circledR}$ sufficient to cover the indicated region in a thin layer.

The initial consultation included a questionnaire with general questions about the importance of look, elasticity and sensitivity of the nipple and areola area. Each subject received a complete medical breast examination performed by physicians and a specific examination of the areola and nipple.

After 1, 2 and 3 months participants filled in a questionnaire about personal opinion on the effects of the ointment; in addition the team doctors conducted an examination of the breast and the nipple-areola complex.

Breast examination performed by the medical team: As criteria a pre-established scale was used, scale provided by the research sponsor. For each parameter followed, the examiner recorded a mark from 1 to 10,1 is the minimum score and 10 is the best score. Parameters: elasticity, sensitivity, look of the area. In addition, adverse or allergic reactions occurring during the study and other noticed changes were recorded.

\section{Results}

\section{Baseline Data}

At the first consultation and completing the initial questionnaire, most participants had the impression that the look, elasticity, and sensitivity of the nipple and areola are very important for erotic satisfaction and positive self-perception, but also important for the specific look of the whole breast (49 women - 96\%). Only one person considers that the look of the breast is not important, one other person has no opinion, each representing a rate of $2 \%$. Both subjects were older, 49 , respectively 52 years old, and their school-level was secondary school, re- 
spectively vocational school (low education level).

Figures 1-4 show the personal opinion about the importance and appearance of the nipple and areola area of the study participants.

The effects of daily application of the guaiazulene ointment on individual perceptions are shown in Figures 5-7. Changes observed by participants: $37 \%$ (19 women) observed an increase in the elasticity of the nipple and areola area; $39 \%$ (20 women) had no opinion and 24\% (12 women) did not notice any change. A positive change of the look of the nipple and areola area was observed by 33\% (17 women), 51\% (26 women) had no opinion and $16 \%$ ( 8 women) did not notice any improvement. An increase in sensitivity of the nipple and areola area was felt in $31 \%$ of subjects ( 16 women), $31 \%$ ( 16 women) had no opinion and $37 \%$ (19 women) did not notice any change. $98 \%$ (50 women) of the participants expressed their wish to continue using Garmastan, 2\% (1 woman) had no opinion.

The scores given by the evaluating doctors after the breast, nipple and areola examination between the first and the last visit revealed improvements in all investigated parameters (Figure 8). Especially the sensitivity of the area was increased by $63 \%$; also the elasticity increased by $36 \%$. The overall look of the nipple and areola area has increased by $8 \%$.

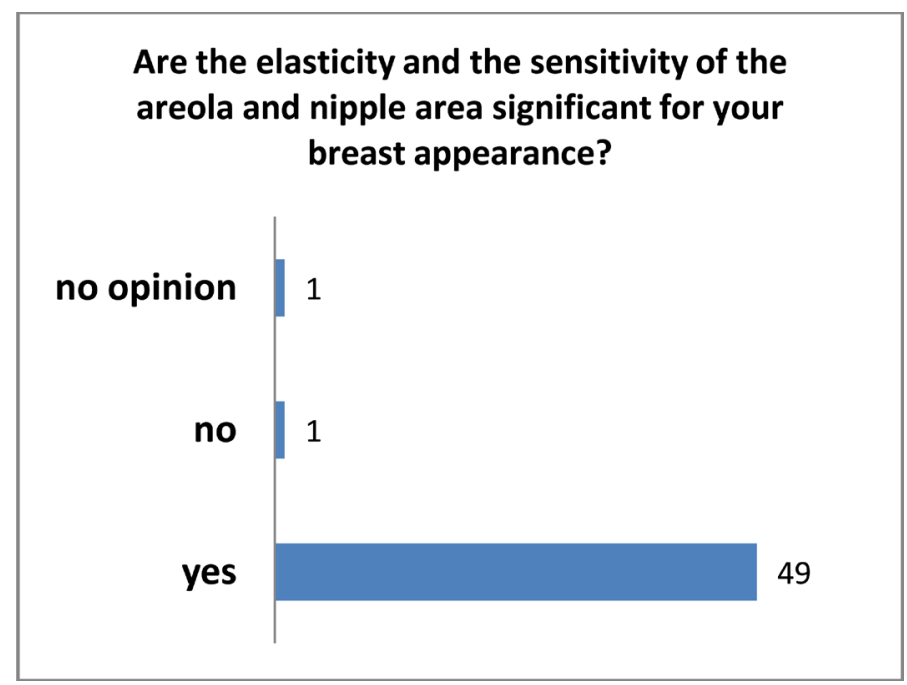

Figure 1. Participant's opinion on significance of elasticity and sensitivity of nipple and areola area.

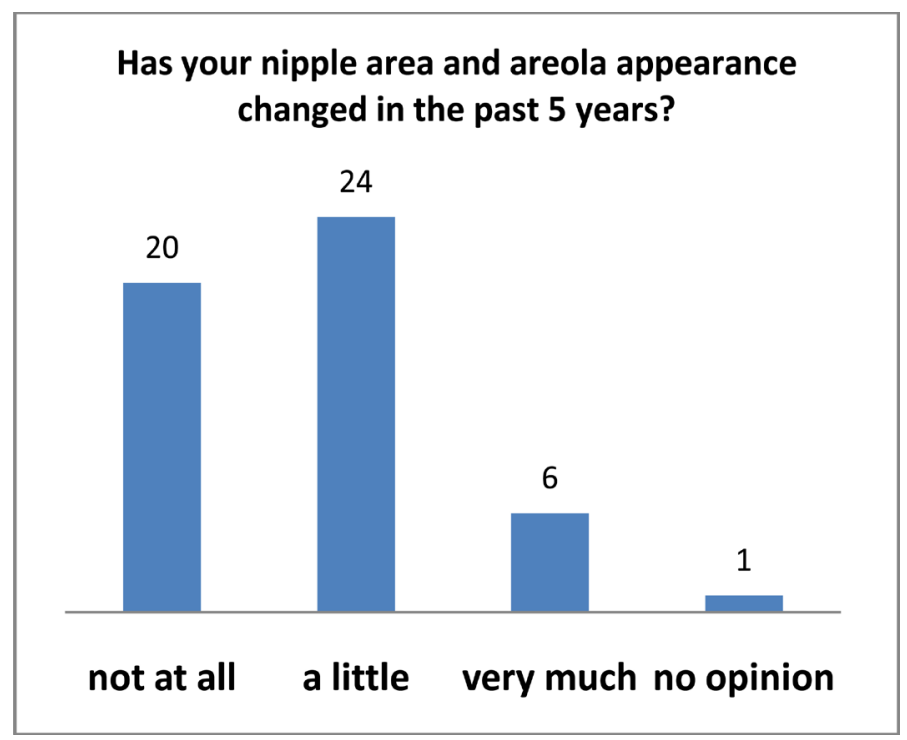

Figure 2. Participant's opinion on change of nipple and areola area during last 5 years. 
Has the sensitivity to touch your nipple area and areola changed in the past 5 years?

39

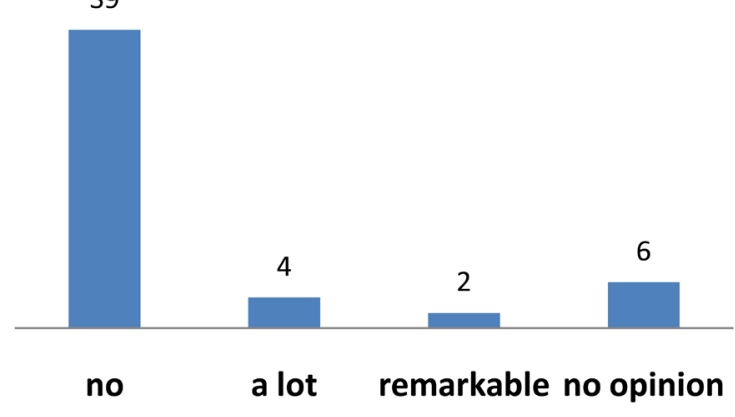

Figure 3. Participant's opinion on change of sensitivity of nipple and areola area in the last 5 years.

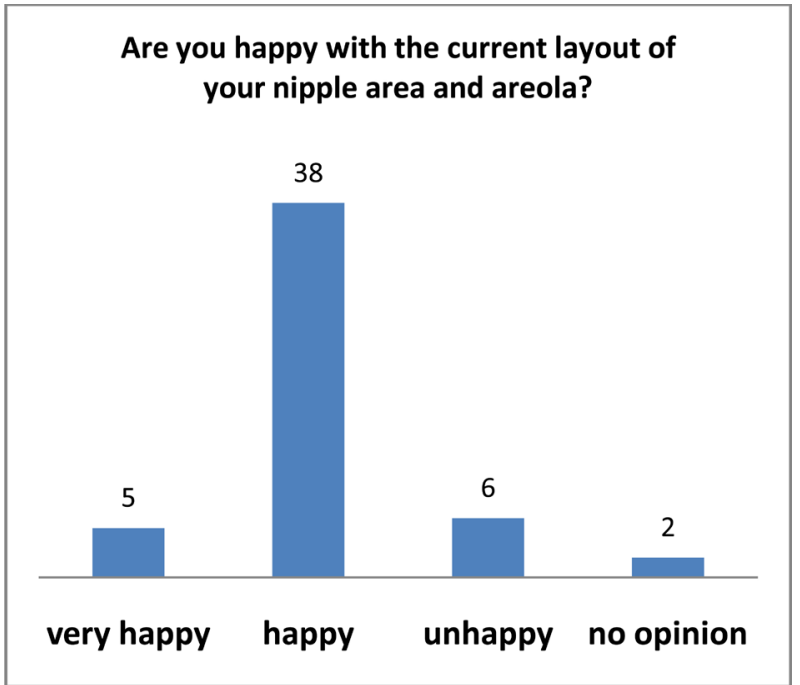

Figure 4. Participant's self-assessment of layout of nipple and areola area.

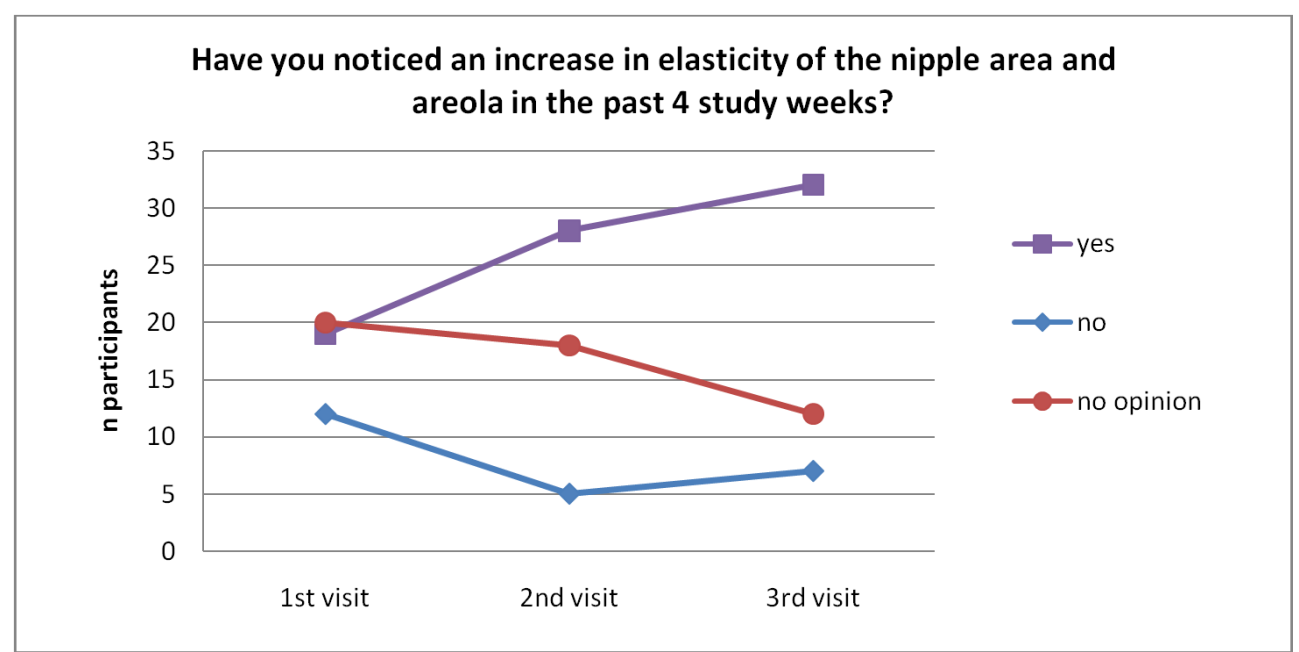

Figure 5. Participant's self-assessment of change in elasticity of nipple and areola area during the study period. 


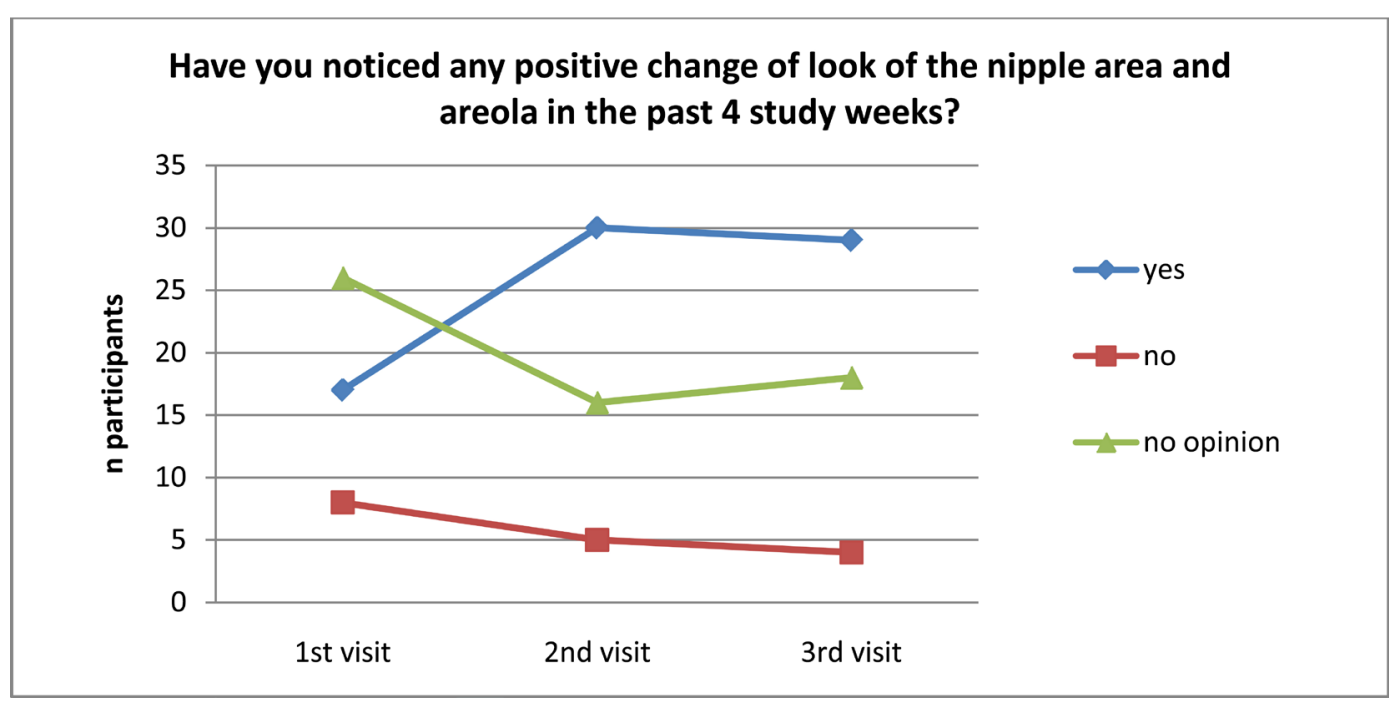

Figure 6. Participant's self-assessment of change of look of the nipple and areola area during the study period.

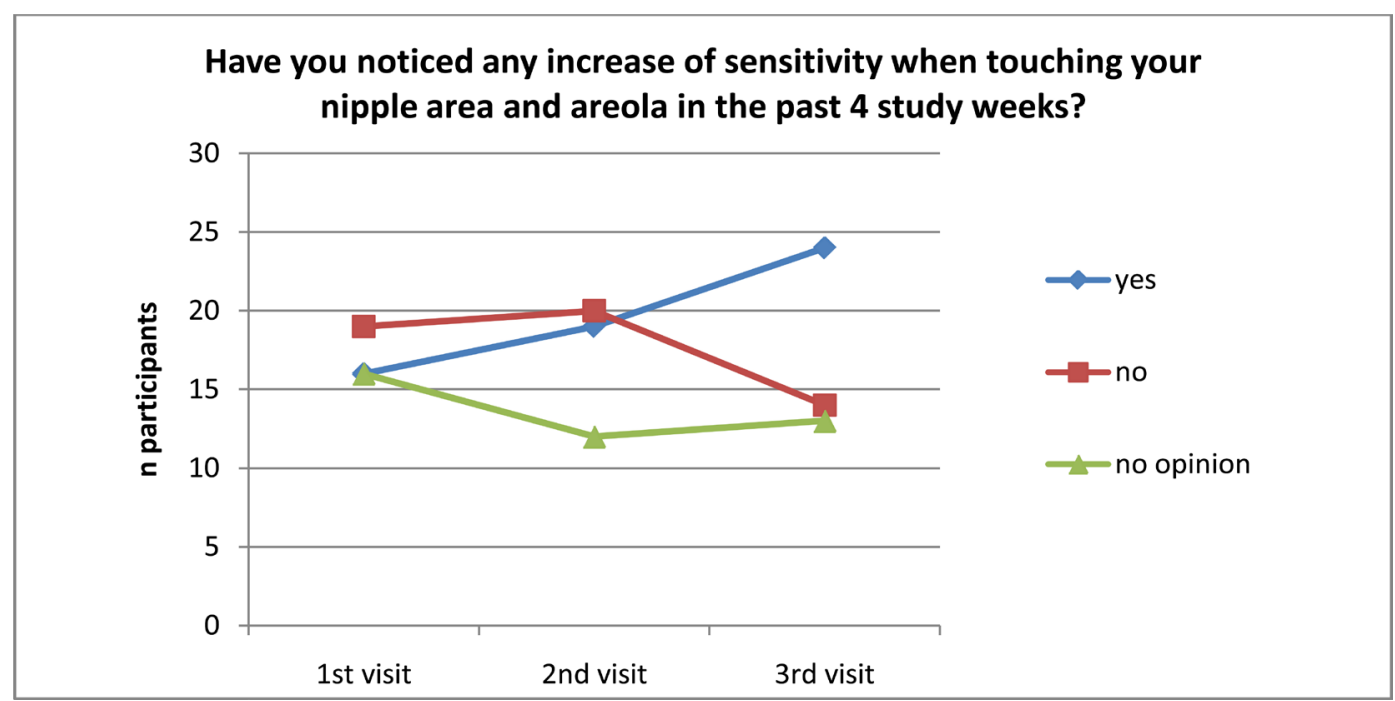

Figure 7. Participant's self-assessment of change of sensitivity of nipple and areola area during the study period.

No adverse reactions were noticed during the study.

\section{Discussions}

The results of this observational study show a beneficial effect of Garmastan ${ }^{\circledR}$ on women's breasts, especially the nipple and areola area. The active ingredient in the used ointment is guaiazulene. This compound has antiinflammatory and antioxidant properties [4] [10] [11]. Guaiazulene can safely be used as a natural antioxidant in cosmetic ointments [12]. Azulenes are widely used not only in medicine but also for cosmetic purposes [13], improving the condition of sensitive skin areas and preventing small wounds and infections. The main function of the specialized dermis of the areola is to protect the breast skin from wear, cracking, or irritation and possible infections. All this can also compromise the look of the skin. The results of this study show that in this sensitive area, the application of the guaiazulene-containing ointment shows its beneficial effects, especially by improving the sensitivity and elasticity of the investigated nipple and areola area. Being water-soluble, this ointment can also easily be applied and removed. To our knowledge, no other study has been performed to specifically address the effect of a cosmetic to the aspect and sensitivity of the nipple-areola complex in non-breastfeeding women. The limitation of this study is the non-availability of a control group and the fact that the results are 


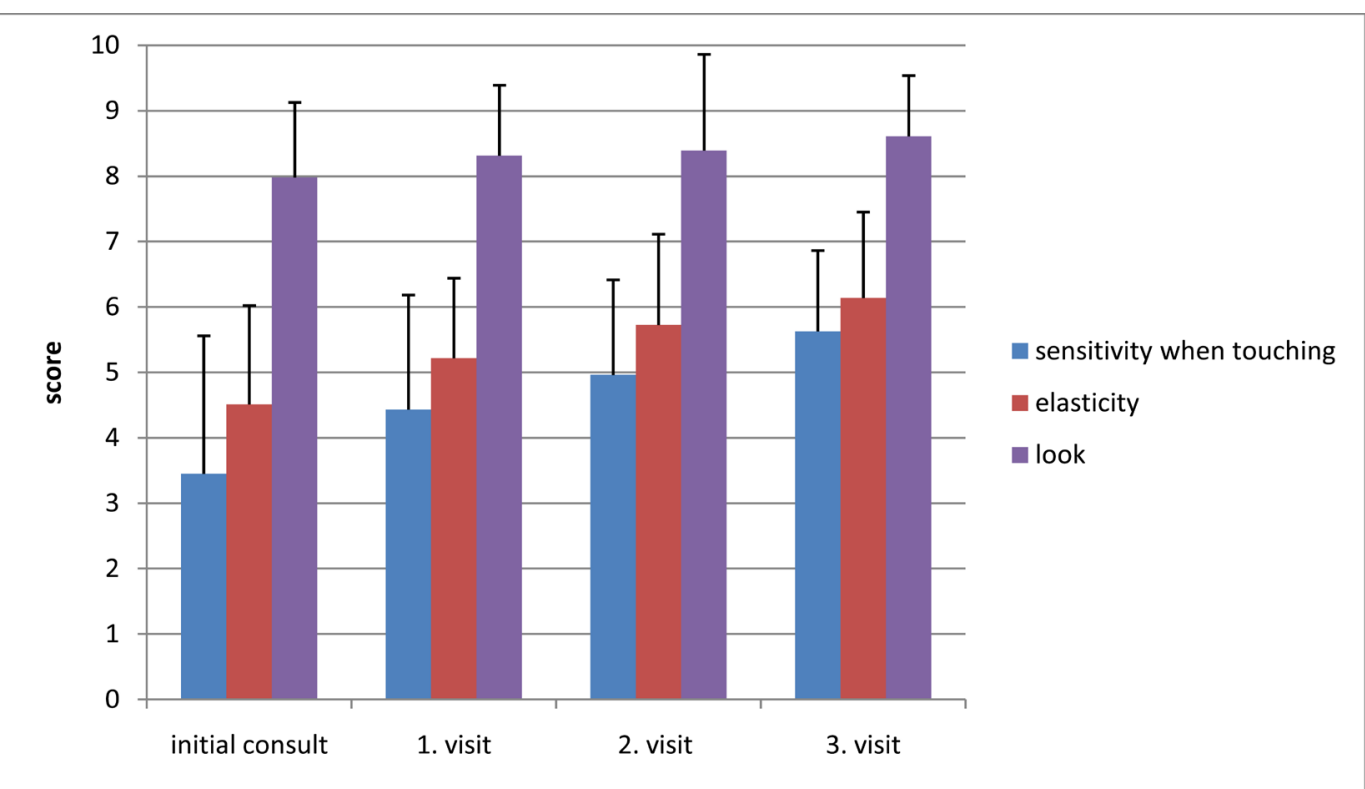

Figure 8. Scores (mean \pm SEM) for sensitivity when touching, elasticity and look of nipple and areola area given by the evaluating doctors after the breast, nipple and areola examination. Statistical differences from initial consult to the $3 \mathrm{rd}$ visit according to student's t-test for paired data: sensitivity when touching, $\mathrm{p}<0.001$; elasticity, $\mathrm{p}<0.001 ;$ look, $\mathrm{p}<0.01$.

based on observation and self-report evaluation. However, the reported beneficial effect of the used ointment should enable further more complex investigations in improving the health of this highly sensitive skin area of women.

In conclusion, the use of Garmastan ${ }^{\circledR}$ ointment is able to improve sensitivity and elasticity of the nipple and areola area of the breasts also of non-breastfeeding women.

\section{References}

[1] Nicholson, B.T., Harvey, J.A. and Cohen, M.A. (2009) Nipple-Areolar Complex: Normal Anatomy and Benign and Malignant Processes. Radiographics, 29, 509-523. http://dx.doi.org/10.1148/rg.292085128

[2] Levin, R. and Meston, C. (2006) Nipple/Breast Stimulation and Sexual Arousal in Young Men and Women. The Journal of Sexual Medicine, 3, 450-454. http://dx.doi.org/10.1111/j.1743-6109.2006.00230.x

[3] Amato, L., Berti, S., Chiarini, C. and Fabbri, P. (2005) Atopic Dermatitis Exclusively Localized on Nipples and Areolas. Pediatric Dermatology, 22, 64-66.

[4] Schilcher, H., Imming, P. and Goeters, S. (2005) Pharmacology and Toxicology. Chamomile: Industrial Profiles, 245.

[5] Richter, M. (1959) Mastitisprophylaxe und Pflege der Brust während der Stillzeit. Deutsche Hebammen, Zeitschrift, 6.

[6] Jauch, W. (1960) Zur Frage der Behandlung des schmerzhaften Milcheinschusses. Deutsche Hebammen, Zeitschrift, 9.

[7] Daniel, W. and Prockl, K. (1964) Experiences with Garmastan Ointment as Mastitis Preventive Agent. Wiener Medizinische Wochenschrift, 114, 149-150.

[8] Api, M., Sivri, D., Api, O., Görgen, H., Çetin, A. and Yayla, M. (2005) Prevention of Nipple Cracks with Guaiazulene versus Breast Milk in Nursing Mother: A Randomized, Controlled, Double-Blind Trial. Journal of the Turkish German Gynecological Association, 6, 279-284.

[9] Gunes, T., Akin, M.A., Sarici, D., Hallac, K., Kurtoglu, S. and Hashimoto, T. (2013) Guaiazulene: A New Treatment Option for Recalcitrant Diaper Dermatitis in NICU Patients. The Journal of Maternal-Fetal \& Neonatal Medicine, 26, 197-200. http://dx.doi.org/10.3109/14767058.2012.722711

[10] Guarrera, M., Turbino, L. and Rebora, A. (2001) The Anti-Inflammatory Activity of Azulene. Journal of the European Academy of Dermatology and Venereology, 15, 486-487. http://dx.doi.org/10.1046/j.1468-3083.2001.00340.x

[11] Kourounakis, A.P., Rekka, E.A. and Kouronakis, P.N. (1997) Antioxidant Activity of Guaiazulene and Protection against Paracetamol Hepatotoxicity in Rats. Journal of Pharmacy and Pharmacology, 49, 938-942. http://dx.doi.org/10.1111/j.2042-7158.1997.tb06140.x 
[12] Toğar, B., Çelik, K. and Türkez, H. (2015) In Vitro Cytotoxic, Genotoxic and Antioxidant/Oxidant Effects of Guaiazulene on Human Lymphocytes. Brazilian Archives of Biology and Technology, 58, 61-67.

[13] Food and Drug Administration (1984) Cosmetic Product Formulation and Frequency of Use Data. FDA Database.

\section{Submit or recommend next manuscript to SCIRP and we will provide best service for you:}

Accepting pre-submission inquiries through Email, Facebook, LinkedIn, Twitter, etc.

A wide selection of journals (inclusive of 9 subjects, more than 200 journals)

Providing 24-hour high-quality service

User-friendly online submission system

Fair and swift peer-review system

Efficient typesetting and proofreading procedure

Display of the result of downloads and visits, as well as the number of cited articles

Maximum dissemination of your research work

Submit your manuscript at: http://papersubmission.scirp.org/ 